\title{
Qual é a importância dos congressos científicos? Visões de pós-graduandos e docentes da Química de uma universidade pública
}

\author{
What is the importance of Scientific Congresses? Conceptions of postgraduate students and \\ professors of Chemistry from a public university \\ ¿Cuál es la importancia de los Congresos Científicos? Visiones de estudiantes de posgraduación y \\ profesores de Química en una universidad pública
}

\author{
Yana Bárbara da Silva Teixeira \\ ORCID: https://orcid.org/0000-0003-0307-0891 \\ Universidade Federal do Amazonas, Brasil \\ E-mail: ybarbarateixeira@gmail.com \\ Ettore Paredes Antunes \\ ORCID: https://orcid.org/0000-0002-4200-5980 \\ Universidade Federal do Amazonas, Brasil \\ E-mail: ettore.ufam@gmail.com
}

\begin{abstract}
Resumo
Compreender o que pensam os alunos e professores de cursos superiores de Química sobre a Ciência e sobre o trabalho científico é significativo, tanto no aspecto de diagnóstico quanto para elaborar reflexões sobre a formação de futuros cientistas. Uma discussão pouco explorada na literatura é a importância dos congressos no processo de formação acadêmica na opinião de membros dessa comunidade. Esta pesquisa é do tipo qualitativa, na qual foram analisadas as respostas de um grupo de sujeitos (alunos de pós-graduação e professores) dadas às perguntas: Você costuma ir em congressos científicos? Qual a importância dos congressos científicos na formação científica?. As análises foram feitas utilizando a Análise Textual Discursiva e foi possível concluir que a preferência maior desses sujeitos é a de frequentar congressos específicos da área, dos quais a maioria participa pelo menos uma vez ao ano, principalmente com o objetivo de se atualizar sobre as novidades na pesquisa e interagir com outros pesquisadores.

Palavras-chave: Congressos científicos; Formação de cientistas; Comunicação científica.
\end{abstract}

\begin{abstract}
Understanding what students and professors of Chemistry think about Science and scientific work, both in terms of diagnosis and reflections on the education of future scientists. A little explored discussion in the literature is the importance of Scientific Congresses for academic formation in the opinion of members of this community. A qualitative research was carried out, in which were analyzed the answers of a group of subjects (postgraduate studentes and professors) given to some questions: Do you usually go to scientific congresses? What is the importance of scientific congresses in scientific education?. The analysis was developed using the Discursive Textual Analysis and it was possible to conclude that the majority prefer to attend specific congresses of the field, and most of them participate at least once a year, mainly with the purpose of identifying themes there are commonly presents in the researches and interacr with others researchers.
\end{abstract}

Keywords: Scientific congresses; Scientists education; Scientific communication.

\footnotetext{
Resumen

Compreender lo que piensan los estudiantes y profesores de los cursos superiores de Química sobre la Ciencia y el trabajo cientifico es significativo, tanto por el diagnóstico como para elaborar reflexiones sobre la formación de los futuros científicos. Una discusión poco explorada en la literatura es la importancia de los Congresos Científicos en la formación académica en la opinión de los membros de esta comunidade. Se realizó una investigación cualitativa en la que se analizó las respuestas de un grupo de sujetos (estudiantes de posgraduación y profesores) para perguntas: ¿Suele asistir a congresos científicos? ¿Cuál es la importancia de los congresos científicos en la formación científica?. Las análisis se realizaron mediante el Análisis Textual Discursivo y se pudo concluir que la mayoría prefiere asistir a congresos específicos de el campo, y la mayoría participa al menos una vez al año, principalmente con el objetivo de actualizarse sobre los temas investigados y interactuar con otros investigadores.
}

Palabras clave: Congresos científicos; Formación de científicos; Comunicación científica. 


\section{Introdução}

Um cientista é, muitas vezes, imaginado no feitio de um "cientista maluco", o qual é caracterizado por ser um gênio trabalhando de forma reclusa em um laboratório. Essa é uma visão individualista e elitista, apontada por Cachapuz e colaboradores (2005) como uma das sete visões inadequadas sobre a Ciência. Na verdade, a Ciência é construída através do trabalho coletivo de cientistas no mundo todo, os quais compartilham com outros suas pesquisas e possibilitam o desenvolvimento do conhecimento científico.

O cientista, como indicado por Oliveira e Alvarado (2008), é alguém que passou por uma formação e, por isso, é capaz de contribuir para o desenvolvimento da sua área de atuação através de seus trabalhos publicados na literatura. Essa formação é comum a todos os cientistas e os une enquanto comunidade, como enfatizado por Kuhn (1998):

[...] uma comunidade científica é formada pelos praticantes de uma especialidade científica. Estes foram submetidos a uma iniciação profissional e a uma educação similares, numa extensão sem paralelos na maioria das outras disciplinas. Neste processo absorveram a mesma literatura técnica e dela retiraram muitas das mesmas lições (Kuhn, 1998, p. 220).

Kuhn (1998) afirma que, apesar dos diferentes níveis (pesquisador, técnico etc.) e grupos (químicos, físicos, biólogos etc.) dentro da comunidade científica, o pertencer à comunidade científica é estabelecido por "participar de sociedades profissionais, ler periódicos especializados" (Kuhn, 1998, p. 221). Isto cria uma identidade em comum para os cientistas, como indicado por Fourez (1995):

[comunidade científica] é uma confraria onde os indivíduos se reconhecem como membros de um mesmo corpo. [...] Em cada caso, temos um grupo social que se autodefiniu de acordo com sua atividade, cujos membros se reconhecem entre si e que tem, portanto, a sua coerência própria (Fourez, 1995, p. 93).

Esse reconhecimento também é definido pelas pesquisas realizadas, as quais possuem temas em comum e muitas vezes compartilham um objetivo. Cobern e Fuentemayor, citados por Alvarado e Oliveira (2008, p.17), afirmam que os cientistas reconhecem como comunidade científica as universidades e seus laboratórios, pelos campos de interesse e pela conexão entre eles através de periódicos, sociedades e eventos. Hagstrom, citado pelos mesmos autores (Oliveira, 2008, p. 18), aponta que o cientista se sente pertencente a uma comunidade científica devido a esse intercâmbio de informação.

Os eventos científicos, como indicado por Lacerda (2008) possuem como objetivo possibilitar tal troca de informações entre profissionais. As reuniões de cientistas para se comunicarem sobre seus trabalhos é uma tradição antiga da comunidade; Spiess e Mattedi (2020) apontam que isso se originou no século XVII com a Royal Society e outras academias. Essa era a forma de trocarem experiências, conhecer o que o outro estava pesquisando, apresentar sua pesquisa, receber críticas e ajuda, ter a chance de se atualizar no progresso da área e, em geral, se comunicar com seus iguais.

Os congressos realizam essa tarefa de viabilizar a comunicação e divulgação científica. Campello (2000) define congresso como:

um evento de grandes proporções, de âmbito nacional ou internacional, que dura normalmente uma semana e reúne participantes de uma comunidade científica ou profissional ampla. Hoje, praticamente todas as áreas do conhecimento realizam, através de suas sociedades e associações, pelo menos um congresso de âmbito nacional ou internacional, que ocorre a intervalos de dois ou mais anos (Campello, 2000, p. 56).

Já a definição da Coordenação de Aperfeiçoamento de Pessoal de Nível Superior (CAPES) é:

reunião ou encontro de pesquisadores e/ou profissionais com interesse em pesquisa acadêmica com vistas à apresentação de resultados de pesquisa em andamento, de desenvolvimentos em uma dada linha de pesquisa ou estado 
da arte em um dado campo ou tópico de interesse. Pode incluir várias atividades, tais como mesas-redondas, conferências, simpósios, palestras, comissões, painéis, minicursos, entre outras (CAPES, 2018).

Portanto, os congressos são uma oportunidade para divulgação científica, pois contam com a participação de grande número da comunidade científica, desde estudantes a pesquisadores e professores, apresentando suas pesquisas em diversas atividades. Além disso, a participação em congressos colabora para o desenvolvimento do pensamento crítico do pesquisador, o qual envolve a "capacidade de analisar ideias ou factos de forma objetiva, racional e lógica, de forma a deduzir respostas ou soluções racionais" (Barreiro, et al, 2021, p. 5). De forma que estas habilidades estão sendo exercidas e aprimoradas, na verdade, desde a escrita de um trabalho acadêmico; durante todo esse processo, durante os congressos e até mesmo durante acontecimentos futuros a partir de experiências em eventos científicos.

\section{Como funcionam os congressos científicos?}

Para a realização de um congresso científico é criado um comitê responsável por sua organização. Esse comitê determina local, data e hora do evento, temáticas a serem abordadas, o processo de inscrição, incluindo o valor, o processo de submissão, avaliação e aprovação de trabalhos, assim como a sua publicação em anais posteriores e a emissão de certificados; também determina atividades diversas a serem realizadas, convidados palestrantes e outros. De acordo com Rodrigues, Carneiro, Ramon e Marcon (2020), é recomendado que cada trabalho seja avaliado por dois pareceristas e que um terceiro seja consultado em caso de avaliações discrepantes. Todas as informações aos participantes são divulgadas no site do evento, bem como a lista de submissões aprovadas e o cronograma do congresso. Por serem muitos detalhes a coordenar, o comitê pode utilizar de recursos que o auxiliem, como a plataforma Even3, a qual aloca eventos, ou Journal and Event Management System (JEMS), utilizado pela Associação Universidade em Rede (UniRede) por ser “um sistema para submissão, revisão, discussão e seleção de artigos para eventos científicos da Sociedade Brasileira de Computação (SBC)" (Rodrgiues, Carneiro, Ramon \& Marcon, 2020, p. 207); entre outros.

Um congresso está centrado em torno de atividades que permitem a troca de informações entre os participantes. Inicia-se com a divulgação de seu local e data; os eventos podem ocorrer em diversas regiões e de acordo com isso atraem diferentes públicos. Primeiramente, ocorre a chamada para submissão de trabalhos completos ou resumos de acordo com os temas abordados. Os trabalhos são avaliados pela comissão e podem ou não ser aceitos para apresentação oral, na qual são expostos os resultados da uma pesquisa, que recebe a opinião e sugestões de outros cientistas com diversas posições na comunidade científica.

Os trabalhos completos são apresentados de forma oral, em média de 20 a 30 minutos, e os resumos em forma de pôsteres (um banner contendo uma síntese da pesquisa) fixados em local por onde o público circula, geralmente com apenas cinco minutos, porém com permanência no local de apresentação por duas horas ou mais. Ambas as modalidades possuem avaliadores. As pesquisas apresentadas podem tanto estar finalizadas quanto em desenvolvimento. Os trabalhos apresentados nos congressos são publicados na forma de anais pela instituição organizadora ou por editoras profissionais (Campello, 2000), no entanto, eles não possuem mesmo status que publicações em periódicos, uma vez que o rankeamento da CAPES é recente. Como observado em tabelas de pontuação do currículo Lattes para mestrado/doutorado (Universidade Estadual de Londrina, 2018), a publicação em periódico de Qualis A1 agrega 20 pontos, enquanto que a publicação de trabalho completo em anais de congressos nacionais agrega apenas 4 pontos, sendo resumo diminui para 1 ponto apenas. Outras atividades dos congressos, segundo Campello (2000), são as conferências e palestras feitas por convidados, geralmente por pesquisadores de destaque na área, e as mesas redondas, nas quais convidados debatem certo tema com a plateia.

Spiess e Mattedi (2020) entendem que a posição de um cientista possui influência no espaço que ele detém em um evento, tendo mais visibilidade e recebendo menos críticas quando em comparação com pesquisadores com pouca ou nenhuma 
reputação - por exemplo, os pesquisadores iniciantes que estão apresentando um resumo na forma de pôster possuem apenas cinco minutos de apresentação, enquanto convidados para palestras possuem muitas vezes duas horas. Essa relação de poder presente em eventos científicos também foi objeto de estudo de Silveira, Bufrem e Caregnato (2015), que observaram o comportamento dos cientistas nesses encontros tendo por base teórica os trabalhos de Bourdieu e Goffman.

Durante a pandemia do COVID-19, quando medidas de segurança foram tomadas determinando, principalmente, o distanciamento social, a educação a distância se tornou a modalidade principal para a continuidade do ensino nas escolas, faculdades e universidades. Os eventos científicos precisaram ter sua estrutura e organização repensadas de modo a se adaptarem a esse modelo, em que todo o processo é virtual, até mesmo a execução das atividades. $\mathrm{O}$ uso de recursos como o já mencionado Even3, que facilita a organização de eventos, e o Google Meet, para as apresentações online, foram cruciais para que diversos eventos ocorressem, como o Encontro Nacional de Ensino em Química (ENEQ). Jesus e colaboradores (2020) afirmam que para estudantes do curso de Enfermagem de uma faculdade do Rio de Janeiro, a participação no evento "Webinar da Saúde do Idoso: conscientização contra a violência da pessoa idosa" significou a continuidade da produção acadêmica mesmo em período de pandemia, possibilitando crescimento profissional e contribuindo para a saúde mental dos participantes.

\section{Comunidade e comunicação científica}

A comunicação é o atrativo principal para os participantes do congresso: a chance de trocar informações com vários outros pesquisadores e observar o que está sendo desenvolvido a área, não apenas nas atividades propostas pelos congressos, mas também nas chamadas "conversas informais" que ocorrem nos corredores do local do evento.

Além de tornar possível a comunicação entre os pares, Oliveira e Alvarado (2008) apontam que os congressos são uma forma de validar um campo científico, e isso é evidenciado também por Spiess e Mattedi (2020, p. 459): "os eventos se inserem neste círculo de credibilidade justamente por serem um espaço para o convencimento e a negociação dos fatos e dados científicos, ou seja, uma arena para a construção da credibilidade", credibilidade tanto dos cientistas quanto da sua área de atuação. Ou seja, eles possibilitam a divulgação e a consolidação do conhecimento da área, trazendo o que é feito no laboratório para o público.

A Química possui muitos congressos nacionais importantes que ajudam no desenvolvimento desse campo e suas subáreas, como o Congresso Brasileiro de Química, o Encontro Nacional de Ensino em Química (ENEQ), o Encontro Nacional de Pesquisa em Química, a Reunião Anual da SBQ, e outros. O encontro de químicos no Congresso de Karlsruhe, na Alemanha, é considerado, de acordo com Spiess e Mattedi (2020), o primeiro evento científico internacional, onde os profissionais da área buscaram padronizar a notação química e realizaram discussões sobre peso atômico de elementos, que fomentaram o desenvolvimento da área.

Devido à relevância para a área e para os próprios pesquisadores, existe incentivo para participação em congressos, principalmente dentro da universidade, dos docentes em relação a seus alunos a divulgarem suas pesquisas de iniciação científica. Chauí (2003) enfatiza que essa participação também é valorizada devido ao peso que tem na produção acadêmica dos cientistas, bem como as publicações.

O trabalho de Lacerda (2008) indica que quase 100\% dos universitários de Biblioteconomia, participantes de sua pesquisa, entendem que os eventos científicos são importantes e, ainda assim, apenas 73,4\% deles já participaram de algum. 93,6\% afirmam que a pouca participação deve-se à falta de tempo, sendo que esses acadêmicos são da região Sul do país; muitos pesquisadores de regiões como a Norte e a Nordeste não possuem recursos para participarem de eventos nas áreas centrais (onde são mais comuns), as quais detêm a maior parte dos recursos de incentivo à pesquisa. 
Francisco e Queiroz (2008), ao analisarem trabalhos apresentados nas Reuniões Anuais da Sociedade Brasileira de Química, especificamente com o tema Ensino de Química, entre 1999 e 2006, perceberam que mais da metade dos trabalhos foram provenientes da região Sudeste e afirmam:

O fato da região abrigar um número elevado de Instituições de Ensino Superior (IES) de grande tradição em pesquisa no país [...] justifica, em parte, a relevante contribuição. Há ainda outro aspecto que pode justificar o fato da região Sudeste apresentar a maioria dos trabalhos nas RASBQs no período investigado. Das 8 Reuniões, 7 foram realizadas no Sudeste (6 no estado de Minas Gerais e 1 no estado de São Paulo), aspecto que aparentemente favoreceu muito a apresentação de trabalhos (Francisco \& Queiroz, 2008, p. 2102).

Os autores indicam que quando a reunião ocorreu na região Nordeste, mais trabalhos locais foram apresentados. Portanto, a localidade pode intervir no público que o congresso consegue atingir, pois tem relação direta com a produção de pesquisa e a reputação de cientistas que se desenvolvem em instituições com mais recursos.

Além disso, muitos universitários só passam a se interessar pelos congressos quando participam de iniciações científicas. Silva Júnior e colaboradores (2014) realizaram um estudo com acadêmicos de Odontologia e constataram que $61 \%$ frequentam eventos e, em geral, são incentivadas pelas pesquisas de iniciação científica, a qual iniciam entre o $5^{\circ}$ e $6^{\circ}$ período.

Hayashi e Guimarães (2016) observaram que professores pesquisadores de uma instituição federal superior da região Sudeste entendem os eventos científicos como meio de divulgação de suas pesquisas. O estudo foi feito com docentes de diversas áreas, mas para o interesse dessa pesquisa trazemos os dados obtidos para a área de exatas, em que 82,5\% dos entrevistados indicaram que as apresentações de trabalhos são a atividade mais importante do evento; apesar disso, 82,3\% afirmaram ter participado apenas uma ou duas vezes, e 61,7\% participaram uma vez de evento internacional. Desse modo, apesar da valorização do papel de congressos, conferências e reuniões, e mesmo estando em uma região considerada central, a frequência de participação é baixa.

De forma similar a esses estudos, buscamos observar a relevância, para a comunidade científica da Química de uma instituição federal de ensino superior, dos congressos como meio de comunicação e desenvolvimento de conhecimento, identificando se os docentes possuem papel em influenciar seus orientandos de pós-graduação a valorizar tais eventos.

\section{Metodologia}

A pesquisa é do tipo qualitativa, visto que a análise e interpretação de dados requer, conforme Yin (2016), estar atento ao que existe nas entrelinhas, pois podem revelar informações importantes que consideram também a influência do contexto em que o participante se encontra. Para recolher dados, foram utilizadas as respostas de 35 pós-graduandos em Química e 15 docentes. O presente artigo estuda as concepções de Ciência, comunidade científica e o que se relaciona com ela, como os próprios congressos, projetos de pesquisa e outros; essas observações colaboram na análise do pensamento de acadêmicos sob diferentes enfoques e em contribuições para que se torne cada vez mais complexo e crítico quanto as relações entre a Ciência e o meio econômico, político, entre outros.

As respostas foram sorteadas a partir das diferentes áreas da Química (Analítica, Físico-Química, Orgânica e Inorgânica) e denominados P1, P2, P3 etc. Os pós-graduandos receberam um código composto pelas letras M (mestrado), D (doutorado), e P (pós-doc), as quais representam o nível do curso do entrevistado, um número e, em seguida, o código do docente que o orienta.

Foi utilizado um roteiro de entrevista mais amplo, conforme descrito em Antunes (2017), e que, portanto, no presente projeto buscou-se uma leitura das respostas para algumas perguntas. Para os docentes foi questionado "Qual a importância dos congressos científicos na formação científica?”, já para os pós-graduandos foram feitas duas perguntas: 
Q1. Você costuma ir em congressos científicos?

Q2. Qual é a melhor parte de ir a congressos?

Para analisar as respostas dadas pelos entrevistados, utilizamos a Análise Textual Discursiva, como discutida por Moraes e Galiazzi (2007), consistindo na busca unidades de significado nas falas, ou "trechos importantes", classificando-as em categorias que representem a ideia geral que foi identificada naquela resposta, para em seguida interpretá-las de acordo com o referencial e o enfoque adotados.

\section{Resultados e Discussão}

\section{Frequência em congressos científicos}

Dos 35 pós-graduandos que responderam ao questionamento, 27 (77\%) afirmaram ir frequentemente em congressos, como pode ser observado nos exemplos a seguir:

P1P4 - “Eu tenho ido bastante.”

D1P10 - "Sim. O costume não é tão frequente, pelo menos não era tão frequente, mas ele tem sido. No ano de 2015 eu fui na SBPMat no RJ e também fui no MRS lá em Boston, Massachusetts, e 2016 de novo. Então tem sido regular assim nos últimos três anos, dois anos.”

M1P13 - "Sim, todos os anos eu costumava ir pelo menos na iniciação, esse ano que eu não consegui ir porque ainda não tinha um trabalho, aí já no começo agora desse mês... mas todo ano assim, eu tento ir ao congresso "'

Os entrevistados dessa pesquisa são de uma área considerada central, ou seja, recebem mais eventos científicos em suas localidades, o que diminui o custo de participação, um fator para a maior abrangência dos eventos. Mesmo assim, como será discutido a seguir, a falta de recurso pode ser um empecilho.

Apenas oito participantes relataram pouca frequência em eventos científicos, com dois motivos sendo identificados nas falas. O primeiro motivo é a falta de auxílio institucional: cinco pós-graduandos afirmaram receber poucos incentivos para que conseguissem ir aos congressos, como exemplificado a seguir:

D2P1 - "É... faz... aproximadamente... cinco anos que eu não vou a congresso. Por quê? Quando eu saí do mestrado, que eu vim para cá, infelizmente eu não tenho bolsa e não tenho tido auxílio para ir aos congressos. Eu tenho participado de congressos e conferências menores. Mas, de nível nacional, e até mesmo internacional, faz estes aproximadamente cinco anos que eu não vou."

P1P1 - "Gostaria de ir mais, mas devido a questão financeira eu não vou tanto, porque no meu doutorado eu era CNPQ então eu recebia uma taxa de bancada, que era de quatrocentos reais por mês então, com esse valor eu conseguia ir em dois congressos, um congresso nacional que foi no Brasil e outro congresso internacional ... Agora no pós-doutorado ... a taxa de inscrição do congresso é igual de um professor então, quando a gente está no doutorado é 500 reais, no pós-doutorado é 1500, 1800 reais a inscrição e ai já foi praticamente toda a taxa de bancada que eu tenho pra ir no congresso. Então, eu gostaria de ir muito mais em congressos do que eu vou, eu acho que acrescenta bastante."

D2P7 - "Na graduação eu fui mais em congressos que eram no Maranhão por ter pouco recurso... apesar de ser bolsista CAPES, a gente não tem o auxílio financeiro, então a gente depende da bolsa e por morar em outra cidade 
fica muito mais difícil né, a gente conseguir sair. Então tento ir a congressos mais perto, tipo, aqui em São Paulo e pelo menos uma vez."

Apesar de estar na área central, alguns pós-graduandos são provenientes de outras regiões e dependem do auxílio para viver e prosseguir com seus estudos, de modo que faltam recursos para eventos. Além disso, como mencionado por P1P1, a taxa de inscrição aumenta conforme o nível acadêmico, dificultando ainda mais para quem tem uma condição financeira limitada.

O segundo motivo é o interesse, que diz respeito a comparecer em um congresso apenas quando há algo que seja realmente interessante do ponto de vista do pós-graduando, o que ficou evidente em três respostas, das quais duas são exemplos significativos:

P1P6 - "Geralmente é conhecer alguém, assistir uma palestra de alguém muito famoso, muito conhecido que fez alguma coisa que você se interessa muito."

D1P6 - "Então, eu sou muito, ah não sei, vamos falar que prática. Eu sei que é importante ir a congressos, porém eu trato de ir somente naquele que é muito específico que vai contribuir diretamente no seu trabalho. Eu sou das pessoas que "ah, se vou receber ajuda para ir num congresso de química geral, ok; mas se vou ter que escolher entre um congresso geral e um específico da área, eu vou preferir, se eu sou uma pessoa que tem que pagar, que tenho que ir atrás do financiamento, ir nesse mais específico, embora seja um no ano, um a cada dois anos.

No geral, todos os participantes frequentam eventos de sua área, mas nesse caso é o interesse apenas pelo específico ponto de sua pesquisa ou subárea.

\section{Credibilidade dentro dos congressos científicos}

De acordo com Spiess e Mattedi (2020, p. 453), existe uma hierarquia que envolve a credibilidade dos cientistas e as atividades de um evento científico:

i. Prestígio amplo: cientistas de reconhecimento internacional que, frequentemente, são convidados para as conferências de abertura;

ii. Prestígio intermediário: cientistas convidados/selecionados para a participação das mesas temáticas e coordenação das atividades do evento; $\mathrm{e}$

iii. Prestígio restrito: cientistas que concentram suas comunicações e participações nos grupos de trabalhos.

De maneira resumida, quanto maior a credibilidade de um cientista, mais espaço para apresentação ele terá. Durante a análise do que seria considerado, pelos pós-graduandos entrevistados, como a melhor parte de ir a um congresso, foi possível observar que as opiniões são influenciadas por essa hierarquia, chamada de Pirâmide Reputacional, criando uma hierarquia das próprias atividades, considerando também as interações que essas atividades proporcionam. Foram identificados quatro pontos/interações principais do evento: (1) “Atualização sobre a área", (2) "Interação social”, (3) "Divulgação de pesquisa" e (4) "Turismo". Em uma análise das respostas, buscou-se verificar qual desses pontos foi considerado como o mais importante e, também, a frequência com que todos eles foram mencionados.

"Atualização sobre a área" foi citada por 28 pós-graduandos e foi considerada por 18, de um total de 34 alunos, a parte mais importante de um congresso, pois os mesmos relataram que a melhor parte de participar de um congresso é poder 
saber o que está sendo feito na área, o que está sendo pesquisado, quais são as novidades, qual o caminho que a área está tomando na construção de conhecimento, como fica evidente nas falas a seguir:

D1P12 - "Olha, eu gosto bastante, assim, tem várias palestras, vários pesquisadores de renome que estão ali mostrando o seu trabalho, mas eu gosto bastante da parte da apresentação oral de outros estudantes ou pesquisadores né que mostram os seus trabalhos, porque dá ideia do que está sendo desenvolvido dentro das universidades, dentro dos centros de pesquisa e acaba que nos incentiva e abre novos horizontes para a gente desenvolver, ou clareia, esclarece algumas coisas..."

$D 2 P 7$ - "Eu acho que palestras, tu consegue, mini cursos, por exemplo... tu consegue ter ideia do que tu poderia fazer com aquilo que a pessoa está falando. Então isso te estimula a pesquisar para uma coisa que tu talvez não esteja olhando, só lendo artigos essas coisas. Então área de palestras, mini cursos é bem interessante e principalmente a parte de sessão, quando tu vai olhando o que as pessoas andam fazendo tu vai tendo mais ideia 'podia ter pensado nessa forma...', fazer mais ou menos isso..."

P1P7 - "Eu gosto muito das... o que eles chamam de sessões coordenadas, de assistir o trabalho de outros alunos, para saber, porque aí você tem mais detalhes sobre o que está sendo feito, cursos que tem dentro também, então são coisas mais focadas, eu acho que essa é a melhor parte. O pessoal gosta muito das falas dos grandes pesquisadores,é bom também, mas eu acho que os trabalhos ali das sessões coordenadas são a parte mais interessante para mim."

Os participam buscam identificar o caminho da área como forma determinante do futuro de seus próprios projetos. De acordo com Antunes, Teixeira e Ferreira (2020), os acadêmicos percebem que pesquisas alinhadas aos temas mais relevantes são aquelas que receberão mais recursos e reconhecimento, por estarem de acordo com as demandas sociais ou de órgãos financiadores.

Ademais, as falas apresentadas implicam a existência dessa diferença na reputação dos participantes, principalmente quando P1P7 menciona: "O pessoal gosta muito das falas dos grandes pesquisadores, é bom também, mas eu acho que os trabalhos ali das sessões coordenadas são a parte mais interessante para mim". Ou seja, aqueles que apresentam as sessões coordenadas não são considerados grandes pesquisadores, no entanto, essa atividade é a mais prestigiada pela maioria dos pósgraduandos entrevistados.

Isso acontece por ser inexistente a pressão de se estar na presença de alguém de renome, mas sim com um colega da área, sendo mais fácil a comunicação, a avaliação entre os pares, a contribuição mútua, a troca de ideias, a construção de, até mesmo, uma amizade, um grupo, uma parceria. Além disso, os vários trabalhos nas sessões coordenadas ajudam a perceber a tendência de pesquisa na área.

Interação social diz respeito à possibilidade de conversar com pesquisadores, até mesmo os mais renomados, seja através das apresentações formais ou conversas informais: essa parte do congresso foi mencionada 22 vezes e dez participantes da pesquisa afirmaram que essa é a melhor parte do congresso, como pode ser observado nos seguintes exemplos:

$D 2 P 1$ - "É a interação entre... o professor, o pesquisador, os orientadores, certo? Eu acho que o congresso científico é para trocar ideias, para fazer novos colegas e você poder trocar ideias, fazer um... grupo talvez e discutir sobre determinado assunto, acho que de forma geral, esse é o objetivo de congressos e reuniões. No meu ponto de vista."

D2P5 - "Eu acho que a melhor parte do congresso são as apresentações dos trabalhos, dos pôsteres e eu ter o contato ali, direto com a pessoa ... acaba indo também muitos professores etc., aí você pode reparar, opinião minha, é 
claro, que alunos acabam que perguntam menos, que interagem menos... as sessões de pôsteres são as melhores, porque $99 \%$ são alunos que estão ali, e aí você consegue ter uma discussão muito direta e trocar e-mails. E aí diz: 'Nossa, mas eu fiz tal coisa assim. Ah, mas o mini-artigo tal, eu tenho o review tal. O know-how do meu grupo é tal.' Para mim, é a melhor parte."

Assim como D2P1, outros alunos também indicaram a formação de parcerias como uma consequência importante da interação com outros pesquisadores, pois existe a chance de se formar grupos com cientistas renomados, ou produzir trabalhos de relevância na área com a ajuda de colegas conhecidos no congresso. Isso foi verificado por Schmidt e Ohira (2002) em sua análise de comunicações em eventos de Biblioteconomia e Ciência da Informação entre 1995 e 2000 sobre bibliotecas virtuais e digitais, das quais $64,11 \%$ das publicações possuíam autoria múltipla, uma prática comum na produção de trabalhos.

Mesmo que a parceria não aconteça imediatamente, o networking continua sendo uma peça principal para o crescimento de um pesquisador na comunidade científica a longo prazo, tanto pelas possibilidades de trabalho em conjunto quanto pela simples troca de informações. A hierarquia aqui é evidente na fala de D2P5, que acredita que a interação é mais proveitosa com aqueles menos famosos que participam das sessões coordenadas, pois a possibilidade de uma parceria é maior do que quando se inicia uma conversa com um pesquisador reconhecido.

O congresso como uma possibilidade para divulgação de pesquisa foi mencionado apenas por três alunos de pósgraduação, as falas a seguir são exemplos significativos:

D1P3 - "Você expor seu trabalho, né... Divulgar mesmo o que você está fazendo, ver o que os outros estão fazendo, se tem algo que possa contribuir com o seu..."

P2P4 - "A melhor parte dos congressos, eu gosto muito de apresentar o meu trabalho de forma oral, que a gente tem a discussão ali... Hoje em dia, a única coisa que eu não gosto muito em congresso são os pôsteres, porque você coloca muito trabalho na forma escrita num espaço muito pequeno, onde você mal consegue andar e discutir os trabalhos..."

Mesmo ao mencionar atualizar-se com as pesquisas de seus colegas, o objetivo principal dos entrevistados, muito mencionado em suas falas, é identificar qual daquelas informações apresentadas pode contribuir com o seu trabalho. Portanto, a divulgação não é considerada pelos pós-graduandos como grande atrativo dos congressos, pois a Pirâmide Reputacional para apresentações de trabalhos torna a modalidade pôster difícil de ser apreciada devido ao curto espaço de tempo para expor as ideias da pesquisa. E, no entanto, quando analisada na perspectiva de atualização sobre a área, as sessões coordenadas foram as mais valorizadas, o que indica que a atividade pode mudar de posição na hierarquia de acordo com o objetivo do participante.

Os congressos científicos acontecem em diferentes locais todas as vezes, o que torna a possibilidade de viajar um "bônus" para muitos participantes. "Turismo" foi mencionado um total de sete vezes como, muitas vezes, um decisivo de qual evento participar, como é evidente na fala de P1P1:

P1P1 - "Com certeza, a melhor parte do congresso são as viagens, conhecer os lugares novos... se tem dois congressos específicos da minha área um na cidade linda e outro aqui em Araraquara, por exemplo, que eu posso ir qualquer final de semana, com certeza eu vou escolher primeira opção que aí eu junto o útil ao agradável, a parte de lazer e cultura juntamente com a parte científica." 
O turismo é muito apreciado, pois, mesmo que o congresso seja, como mencionado por Spiess e Mattedi (2020) uma extensão do trabalho feito nas universidades, laboratórios, institutos e organizações, são também um escape da rotina em um ambiente diferente e com experiências diversas, tornando-se assim um misto de lazer e dever científico, como D2P12 apontou "Também quando a gente viaja em lugares que tem uma certa atração turística, a gente sempre gosta, né". Em relação a esse ponto, já é perceptível uma hierarquia externa à estrutura dos congressos científicos, a qual considera a localidade como fator de credibilidade para o evento; se o lugar possui a vantagem turística, existem maiores chances de que os pesquisadores queiram participar.

De modo geral, a fala de D1P13, a seguir, resume qual seria a hierarquia de importância das atividades, ou dos pontos principais de um congresso científico na visão dos 34 pós-graduandos participantes da pesquisa:

D1P13 - "Ah, eu gosto bastante assim, porque a gente vê o trabalho de outras pessoas, a gente tem ideias em cima desses trabalhos consegue ver o que está sendo feito. Ah, gosto das palestras também, a gente acaba conhecendo outros pesquisadores, os pesquisadores também conhecem a gente, a gente começa a ficar mais conhecida no meio, acho que isso é bastante importante também essa parte social então acho que tudo também. Além de passear que sempre é uma cidade diferente que eu ainda não conheço e junta tudo isso."

\section{Diferentes visões sobre congressos científicos: influência da experiência}

Assim como os pós-graduandos, os professores relataram que a atualização sobre a área é um dos pontos principais do congresso científico (oito menções no total), pois colabora na formação científica no sentido de o aluno conseguir entender o que está sendo feito de pesquisa e aprender e ter ideias com os trabalhos de outros colegas para futuras pesquisas, como mencionado nas seguintes falas:

$P 1$ - "A participação nos congressos eu acho que são momentos de a gente ver, trocar experiências e ter uma leve percepção de como as coisas são feitas noutros lugares... e um momento de apreensão de informações para você se dar conta de quais são as questões que estão sendo feitas pelos colegas neste momento..."

$P 3$ - "Eu diria que o congresso é uma vitrine do que se faz no mundo na sua área ou em qualquer área em ciência. Você vai ver como as pessoas fazem, o que fazem, então você vai poder julgar até mesmo o que você está fazendo, qual a importância, qual... o quanto a sua pesquisa tá inserida no contexto daquela área que cê vai no congresso. Por isso tem uma importância né. E você pode ter contato com outras pessoas, trocar ideias né fora do seu país então isso é bastante importante. Eu diria até que faz parte também da formação do cientista em si."

Para os professores, os congressos mais bem vistos são os internacionais, pois na hierarquia da pesquisa científica do mundo, o Brasil é visto como limitado por diversos problemas, mesmo que possua potencial intelectual, como mencionado por P5:

P5 - “...eu gosto de estimular meus alunos irem em congressos, especialmente os congressos internacionais ou os nossos no Brasil que tem caráter internacional, para eles verem o quanto eles estão expostos, para eles perceberem que... tá, a gente pode ter mais dificuldades com falta de reagentes, com falta de instrumental, mas que estamos trabalhando em nível de competitividade intelectual e de resultados com o pessoal dos centros mais avançados, eu digo mais avançados em tecnologia e em equipamento..." 
As sessões coordenadas também são bem vistas pelos docentes pela diversidade de pesquisas que podem ajudar de diferentes maneiras o pós-graduando a se integrar na área, colaborando para sua futura carreira profissional. Por esses mesmos motivos, a interação social é igualmente valorizada (sete menções ao todo):

P9 - "Eu posso contar por história própria. Eu consegui o meu estágio no exterior a partir do congresso científico. Eu tinha vontade de trabalhar com o professor Christopher Breth, e ele passou no meu painel, foi uma discussão que ele bateu o olho no meu trabalho, gostou, ficou discutindo, nessa discussão, que durou uma meia hora, que ele ficou discutindo o trabalho inteiro, eu conhecia ele, perguntei como que era, e foi a oportunidade de fazer contato..."

P14 - “...relacionamento profissional em pesquisa, em Ciência é extremamente importante porque há grande chance de ideias complementares em Ciência. E essas ideias só vão poder ser complementadas se houver a conversa entre pessoas que estão com aquelas ideias em mente... Se você vai, se as pessoas vão para um evento e eliminam essa possibilidade eu acho que grande parte dos benefícios que poderiam vir do evento vai ficar comprometido em função dessa falta de conversa, dessa falta de interlocução durante os congressos."

A oportunidade de divulgar sua pesquisa é bastante relevante aos olhos dos professores, como mencionado por cinco deles, pois é o momento de exposição do aluno, de compreensão de seu lugar na área, das perspectivas e críticas de seus colegas de profissão; é também, de certa forma, uma integração na área. Esses pontos são claros nas seguintes falas:

$P 7$ - "O aluno poder ir lá, poder expor o seu trabalho, isso exige um preparo prévio e ele vai ter que expor as suas ideias, expor seu trabalho e vai estar sujeito às pessoas estarem argumentando, falando por que você fez isso, por que você resolveu aquilo, então, isso na minha opinião, traz amadurecimento muito grande para o aluno. Ele vai poder ter uma visão muito bem clara da onde ele está em termos de pesquisa com os demais colegas, está fazendo algo que está muito abaixo do pessoal que está fazendo, está fazendo algo que já foi feito, vai ter que pensar. Então ele vai poder ter esse feedback e, dependendo do congresso, ele também vai poder ouvir os grandes pesquisadores na área. Isso, na minha opinião, é bastante importante para a formação.

$P 16$ - "Então, você começa desde a graduação, vai fazer apresentação de pôster num congresso de iniciação científica da própria universidade, uma coisa doméstica pra ele perder o medo, perder a vergonha. Então, acho que é fundamental e isso é... Mesmo quando entra já na vida profissional, de Ciência, tem que continuar indo para congresso, internacional, dando a cara a tapa, mostrando o que você faz, pra ouvir a crítica. A crítica também vem através do parecer do editor da revista ou coisa assim... Esse processo também envolve exposição, mas não envolve o dedo na cara e não envolve essa troca dinâmica e imediata de informações. Então, eu acho que amadurece muito a participação do congresso."

A apresentação oral possibilita que "críticas e sugestões sejam feitas na hora, de forma a permitir uma retroalimentação instantânea, podendo envolver vários pontos de vista" (Campello, 2000, p. 53). Dessa forma, o aluno consegue melhorar seu trabalho a partir dos diversos enfoques trazidos por outros pesquisadores. Ademais, como observado por Azevedo e colaboradores (2020), os docentes buscam sempre desenvolver projetos, mesmo que a divulgação final não seja através de congressos.

Nenhum dos docentes aprecia a associação do turismo e lazer a uma viagem ao congresso, pois isso está distante do propósito de participar de tal evento: 
$P 13$ - "O que tem acontecido é que dependendo do lugar que é feito o congresso, eu vejo mais estudante fora do congresso - fazendo lazer - do que propriamente no congresso..."

P6 - "Se o congresso for sério muito importante. Se a pessoa não for para passear, é muito importante..."

Tanto para docentes quanto para os alunos de pós-graduação, o congresso é um momento importante para a formação, no entanto, estes últimos o entendem também como um momento de escape turístico, pois, muitas vezes, essa é a única viagem que aquele aluno tem condições de fazer. Apenas P9 mencionou a falta de recursos como uma dificuldade para os alunos participarem dos congressos científicos, e mesmo este criticou o turismo:

P9 - “...só que tem que ser mais acessível, está caro para o aluno ir. Está muito caro. Eles estão abusando absurdamente. Os regionais estão caros, imagina os internacionais. Os nacionais mais caros, imagina os internacionais... É um absurdo, para aluno de graduação, mas eu acho que o aluno tem que ir... Só que o aluno tem que se portar no congresso para ir no congresso científico, não para ir para passear. 'O que estou fazendo aqui?' Passear? Congresso é importante, entrar em contato, para o amadurecimento... O problema é que a gente não tem mais poder para frequentá-los. Um por ano e olhe lá. Imagine o aluno de graduação e pós-graduação. Com corte de verba, como é que faz para ir?"

\section{Considerações Finais}

Os congressos são bastante frequentados e considerados importantes pela comunidade científica, pois, através de suas diversas atividades, os pesquisadores podem atualizar-se sobre sua área e participar de eventos específicos, observando os trabalhos apresentados, interagir com seus iguais, formando até mesmo parcerias, além de divulgar sua própria pesquisa para o público. Para os professores, é ainda mais relevante participar de um congresso se o mesmo for internacional, pois seria uma quebra da ideia de que a pesquisa nacional é inferior devido a suas limitações (financeiras, técnicas e outras).

Apesar da diferença de experiência entre pós-graduandos e docentes universitários de longa carreira, o pensamento em relação ao evento científico é similar, visto que fica evidente que o ponto mais valorizado é poder entender as tendências de pesquisa da área, atualizando-se sobre os temas mais relevantes. Logo em seguida, os pesquisadores preocupam-se em criar um networking, socializar com seus pares e compartilhar informações, existindo a possibilidade de formar colaborações com destaques da área.

Os pós-graduandos não demonstraram grande interesse em divulgar suas pesquisas, no entanto, os docentes apontaram que a apresentação do trabalho e o recebimento de críticas e sugestões ajuda na formação científica, auxiliando o aluno a se localizar na área como pesquisador em relação aos seus colegas; de acordo com P7, a exposição "traz amadurecimento muito grande para o aluno".

O "divisor de águas" entre os pensamentos é o turismo. A ideia do lazer simultâneo ao cumprimento do dever científico é apreciada pelos alunos de pós-graduação, e muito criticada pelos professores. Uma razão para a diferença seria que os pós-graduandos, em maioria, dependem de auxílio financeiro para conseguirem participar dos eventos, indicando que não muitos têm a possibilidade de viajar; assim, quando um congresso é realizado em um local turístico ou simplesmente diferente de sua região, a participação é vista como "juntar o útil ao agradável". Porém, apenas P9 mencionou a dificuldade financeira como um obstáculo para os alunos participarem dos congressos, "imagine então internacionais", que são a preferência dos docentes. 
De qualquer maneira, a existência de uma hierarquia dentro da estrutura desses eventos é percebida tanto por pósgraduandos quanto por professores, seja em relação à credibilidade dos cientistas - e os privilégios daqueles considerados renomes em receber mais tempo de apresentação e poucas críticas quando comparados aos pesquisadores iniciantes -, seja em relação à importância das atividades, estando em maior posição as sessões coordenadas devido à diversidade de trabalhos e à interação com vários pesquisadores.

O presente trabalho suscita uma discussão, ainda muito incipiente na literatura, sobre a formação de cientistas e os múltiplos aspectos que influenciam neste processo. Discussões mais aprofundadas dos formatos dos programas de pósgraduação no Brasil, as relações entre orientador-orientando e as relações entre a produção científica e a formação dos professores em nível superior são alguns caminhos para futuras investigações.

\section{Referências}

Antunes, E. P. (2017). Estudo das correlações entre a formação do pensamento sobre ciência e o desenvolvimento do espírito científico na trajetória da graduação à pós-graduação em Química. Dissertação de Doutorado, Universidade Federal de São Carlos, São Paulo, SP, Brasil.

Antunes, E. P., Teixeira, Y. B. D. S., \& Ferreira, L. H. (2020). A Importância da Atividade Científica: concepções dos produtores de conhecimento químico de uma universidade pública. Ciência \& Educação (Bauru), 26. 10.1590/1516-731320200044

Azevedo, J. K. N., et al (2020). Perfil docente do Campus VIII da Universidade Estadual da Paraíba: Ensino, pesquisa e extensão. Research, Society and Development, 9(9), e358997266-e358997266. 10.33448/rsd-v9i9.7266

Bachelard, G. (2013). A Formação do Espírito Científico: contribuição para a psicanálise do conhecimento: Editora Contraponto.

Barreiro, M. P. R., et al (2021). El pensamento crítico y su evaluación en la educación universitaria. Research, Society and Development, 10(3), 1-6. $10.33448 /$ rsd-v10i3.13748

Cachapuz, A., Gil-Perez, D., Carvalho, A. M. P., Praia, J., \& Vilches, A. (2005). A Necessária Renovação do Ensino Das Ciências: Cortez.

Coordenação de Aperfeiçoamento de Pessoal de Nível Superior - Diretoria de Avaliação, CAPES (2016). Considerações sobre classificações de eventos.

Campello, B. S. Eventos Científicos. In: Campello, B. S., Cendón, B. V., \& Kremer, J. M (2000). Fontes de informação para pesquisadores e profissionais (p. 52-68): Ed. UFMG.

Chaui, M. A. (2003). Universidade pública sob nova perspectiva. Rev. Bra. de Edu. (24), 5-15.

Fourez, G. (1995). O método científico: a comunidade científica. In:Construção das Ciências - Introdução à Filosofia e à Ética das Ciências (p. 91-102): Editora UNESP.

Francisco, C. A., \& Queiroz, S. L (2008). The production of knowlegde of chemical education at the annual meetings of the Brazilian Chemical Society: a review. Química Nova, 31 (8), 2100-2110.

Hayashi, M. C. P. I., \& Guimarães, V. A. L (2016). A comunicação da ciência em eventos científicos na visão de pesquisadores. Em Questão, 22 (3), 161-183. $10.19132 / 1808-5245223.161-183$

Jesus, P. B. R. de., et al. (2020). Planejamento e participação de evento científico online como recurso educacional e interativo no ensino EaD: um relato de experiência. Research, Society and Development, 9(9), e333997163-e333997163. 10.33448/rsd-v9i9.7163

Kuhn, T. S. (1975). A Estrutura das Revoluções Científicas: Editora Perspectiva.

Lacerda, A. L. de., et al (2008). A importância dos eventos científicos na formação acadêmica: estudantes de biblioteconomia. Revista ACB, 13 (1), $130-144$.

Moraes, R., \& Galiazzi, M. C. (2007). Análise Textual Discursiva: Editora Unijuí.

Oliveira, M., \& Alvarado, R. U. (2008). A comunidade científica da biblioteconomia e ciência da informação brasileira. Informação \& Sociedade, 18 (1), 1329.

Rodrigues, E. I., Carneiro, M. L. F., Ramon, L., \& Marcon, K. (2020). Papel do Comitê Científico no ESUD: organização e procedimentos. EmRede-Revista de Educação a Distância, 7(1), 206-224.

Silva Junior, M. F., et al (2014). Iniciação científica: percepção do interesse de acadêmicos de odontologia de uma universidade brasileira. Saúde e Sociedade, 23, 325-335. 10.1590/S0104-12902014000100026

Silveira, M. A. A. da., Bufrem, L. S., \& Caregnato, S. E (2015). Scientific events, power relationships and practices of researchers. TransInformação, 27 (3), 199-208. 10.1590/0103-37862015000300002

Schimidt, L., \& Ohira, M. L. B. (2002). Bibliotecas virtuais e digitais: análise das comunicações em eventos científicos (1995/2000). Ciência da Informação, 31 (1), 73-97. 
Research, Society and Development, v. 10, n. 5, e34910515098, 2021

(CC BY 4.0) | ISSN 2525-3409 | DOI: http://dx.doi.org/10.33448/rsd-v10i5.15098

Spiess, M. R., \& Mattedi, M. A. (2020). Eventos científicos: da Pirâmide Reputacional aos círculos persuasivos. Revista Sociedade e Estado, 35 (2), $441-471$. $10.1590 / \mathrm{s} 0102-6992-202035020004$

Universidade Estadual de Londrina (2018). Tabela de Pontuação Lattes. <http://www.uel.br/pos/psicologia/pages/arquivos/Formulario\%20\%20Tabela\%20Pontuacao\%20Lattes\%202018.pdf>.

Yin, R. K. (2016). Pesquisa qualitativa do início ao fim. (1a ed.): Editora Penso. 